\title{
Methods for the verification of protective measures for safety of DC charging stations for electric vehicles Daniel HERBST ${ }^{1}$, Robert SCHUERHUBER ${ }^{1}$ and Ernst SCHMAUTZER ${ }^{1}$
}

\author{
${ }^{1}$ Institute of Electrical Power Systems \\ Graz University of Technology \\ Inffeldgasse 18/I, $8010 \mathrm{Graz}$ (Austria) \\ Phone number: 0043316 873-7551, \\ e-mail: daniel.herbst@tugraz.at, robert.schuerhuber@tugraz.at, schmautzer@tugraz.at
}

\begin{abstract}
Due to the rising number of electric vehicles in operation the handling of charging stations concerning testing and personal safety has been becoming more and more a focus of interest in practice. Currently there are still open questions concerning safe installation, inspection and operation of such charging stations. This paper focuses on protective measures for safety and initial as well as periodic testing of DC charging stations. At the beginning of the work an overview of legal regulations and technical standards for charging stations is compiled. Further on different DC charging processes (of charging stations from different manufacturers in normal operation and in cases of faults) are measured as well as analysed. It shows that DC charging stations of different manufacturers react differently with regard to switch-off behaviour or switch-off times to various fault scenarios.
\end{abstract}

\section{Key words}

Electric vehicle, DC charging station, protection against electric shock, protective measures, initial and periodic verification

\section{Introduction}

Due to the increase of electric vehicles during the last years, charging infrastructure has been expanded throughout all countries. This led to an ever denser network of charging stations for electric vehicles. Throughout Europe as well as in the United States, the number of charging outlets installed is still increasing fast with every year.

As shown in Figure 1, there are more than 135,000 public charging outlets in the enlarged European Union [1] and more than 47,000 in the US in 2017 [2]. According to this growing number of charging outlets a more detailed consideration of safety aspects is required, in particular with regard planning, installation, testing as well as operation of charging stations (EVCS, electric vehicle charging station).

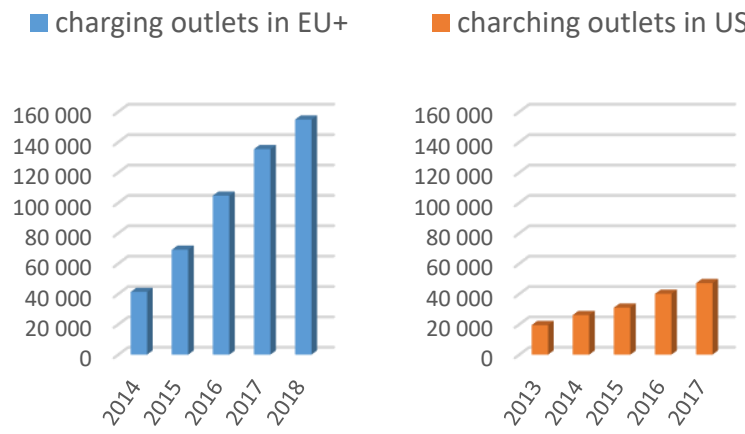

Fig. 1. Total number of public charging outlets for electric vehicles in EU+ (28 European Union member states as well as IS, LI, NO, CH and TR; source [1]) compared with US (source [2])

Basically, today's conductive charging infrastructure mainly consists of AC charging stations on the one hand, on the other hand, of DC charging stations for fast charging. These have been becoming increasingly popular. In principle, AC charging stations can be considered as a kind of smarter power outlets, therefore they can be checked using common installation testing procedures and equipment. For the initial and periodic verification of DC charging stations, however, nowadays neither comparable test procedures exist nor simple devices are commercially available.

In this paper this topic is dealt with in the following way:

- First, the current legal and normative situation is analysed.

- Then measurements and tests, which were carried out on practical charging stations from different manufacturers are discussed.

- Based on the findings gained from these measurements, a proposal for a testing device and reasonable test procedures are derived. 


\section{Regulations and technical standard survey}

The following list of national and international standards provide a rough overview of the large number of applicable standards in the field of charging stations and charging processes for electric vehicles. On one hand, these include standards with regard to the construction of electrical systems supplying charging stations, on the other hand, specific standards relating to charging connectors and processes are listed.

- IEEE C2-2017 2017 National Electrical Safety Code (NESC)

- NFPA 70 NEC 2017 National Electrical Code (NEC) 2017

- IEC 60364 series

Int. resp. ÖVE/ÖNORM E 8001 series

AUT Low voltage electrical installation - measures against electric shock

- IEC 60364-7-722

Int. resp. ÖVE/ÖNORM E 8001-4-722 AUT Low voltage electrical installation - supply of electric vehicles

- IEC 62196 series

Int. resp. OVE EN 62196 series

AUT

Conductive charging of electric vehicles (connectors)

- IEC 61851 series

Int. resp. ÖVE/ÖNORM EN 61851 series AUT Electric vehicle conductive charging system (charging processes)

- DIN VDE V 0122-2-300:2016-04 GER Conformance Test Specification IEC 61851-23, Annex CC (testing standard, DRAFT)

- $\quad$ IEC 61439 series

Int. resp. ÖVE/ÖNORM EN 61439 series Low-voltage switchgear and controlgear assemblies

AUT

Remarks: Internationally valid (Int.), valid in United States (US), valid in Austria (AUT), valid in Germany (GER).

These national and international standards essentially cover the construction and installation of charging stations as well as the principles of charging processes. Standards for initial and periodic verifications of charging stations are currently not available.

\section{Measurements and tests}

To verify the investigations from various standards and also deeper analyse the behaviour of charging stations during normal operation as well as in case of faults, a measurement distribution box was developed and commissioned (see Figure 2), see also [3].

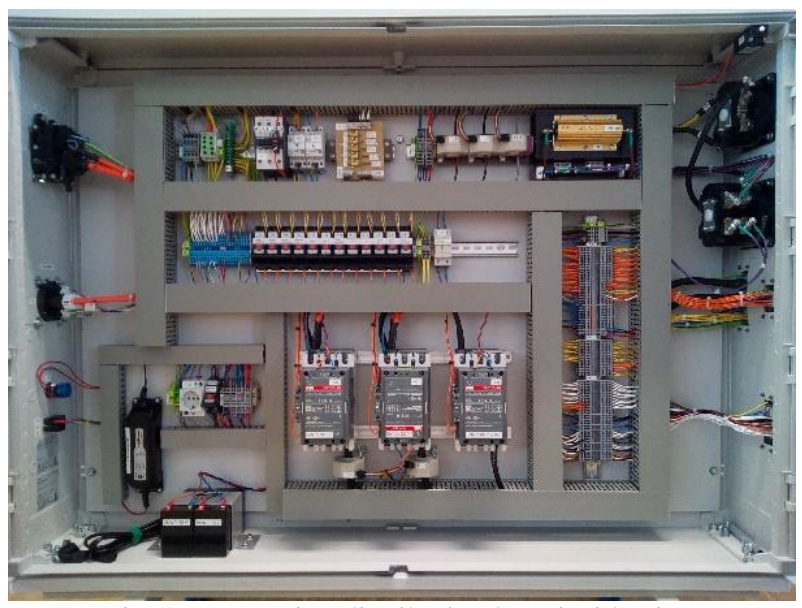

Fig. 2. Measuring distribution box, inside view

In order to measure the different voltages and currents as well as to record the switching states of the contactors with an external multichannel measurement system, a measurement box was set up (see Figure 3).

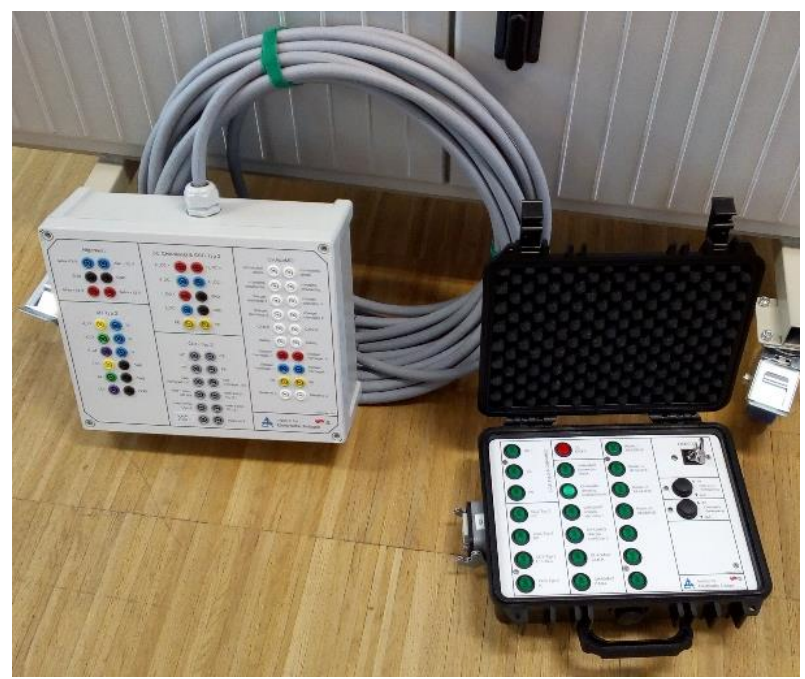

Fig. 3. Accessories for measurement distribution box (left: measurement box; right: remote control)

The measuring distribution box is positioned as an adapter between the DC charging station and the electric vehicle (see Figure 4) in order to carry out measurements and analyses of faultless (normal operation) as well as faulty charging processes at charging stations of different manufacturers.

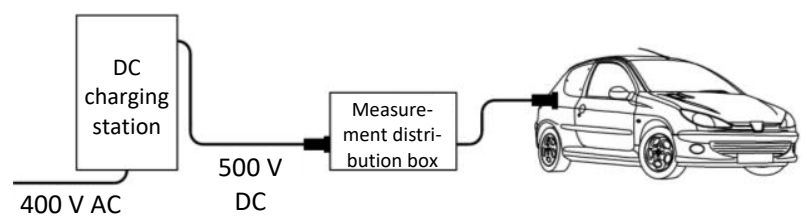

Fig. 4. Principle measurement arrangement

For DC charging stations (connection case "C" according to IEC 61851-1: 2017-2 [4]), the charging cable is firmly connected to the charging station (see Figure 4). Cable sets for charging with Type2, CCS Combo2 and CHAdeMO connectors were prepared to connect the measurement distribution box to the electric vehicle, see Figure 5. 


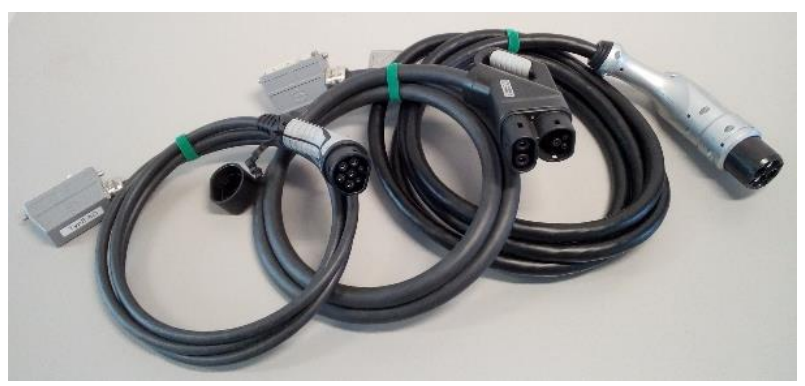

Fig. 5. Cable set for measurement distribution box (left: Typ2; middle: CCS Combo2; right: CHAdeMO)

With help of this measuring distribution box, the following listed fault cases can be created and the behaviour of the charging station can be measured and analysed (also see Figure 6):

a.) Interruption of all signal/communication lines

b.) Interruption of DC load lines

c.) Interruption of the protective earth (PE) conductor

d.) Ground fault

e.) Phase-to-phase fault

f.) Longitudinal and lateral arc faults

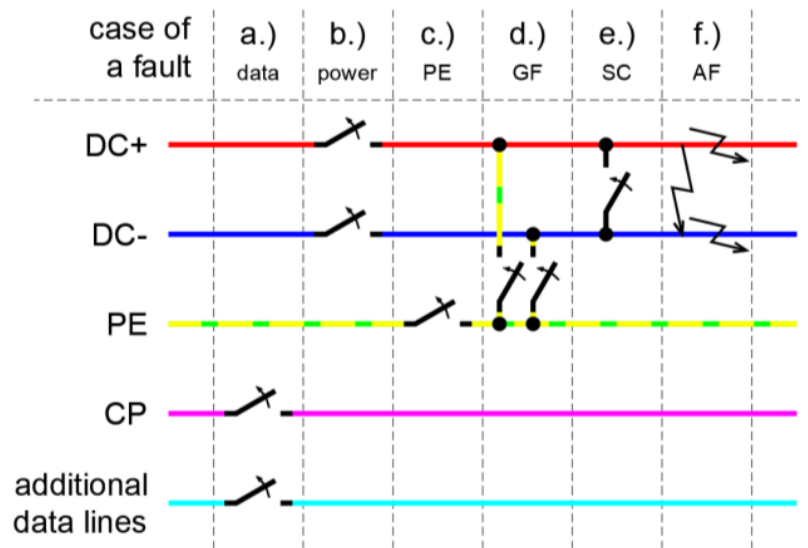

Fig. 6. Different fault cases

As an example, in the next section a selected fault situation is shown and analysed.

Figure 7 shows the measured charging voltage $U_{\mathrm{DC}}$ (left

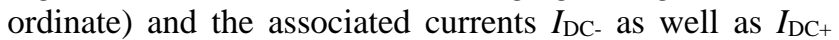
(right ordinate) during a regular DC charging process of an electric vehicle according to mode 4 conformable to OVE/OENORM EN 61851-1:2012-03-01 (CCS, see Annex CC from OVE/OENORM EN 61851-23:2014-12-01 [5]). At the beginning of the charging process $\left(t_{0}=13: 07: 57\right)$, a steeply rising, rectangular voltage peak with a maximum value of $U_{\mathrm{DC}, \max }=460 \mathrm{~V}$ indicates a handshake procedure between the electric vehicle and the DC charging station as well as an associated insulation test of the charging cable. Afterwards DC voltage rises slowly starting from $U_{\mathrm{DC} 0}=370 \mathrm{~V}$ to $U_{\mathrm{DC} 1}=390 \mathrm{~V}$ and remains at this level until the end of the charging process. Concerning the DC charging current, after the handshake has been completed, a steady, ramp-shaped increase can be seen from $t_{1}=13: 08: 10$ to a maximum value of $I_{\mathrm{DC}+\text {,max }}=120 \mathrm{~A}$ at $t_{2}=13: 09: 00$ (this period of time coincides with the rampshaped voltage increase).

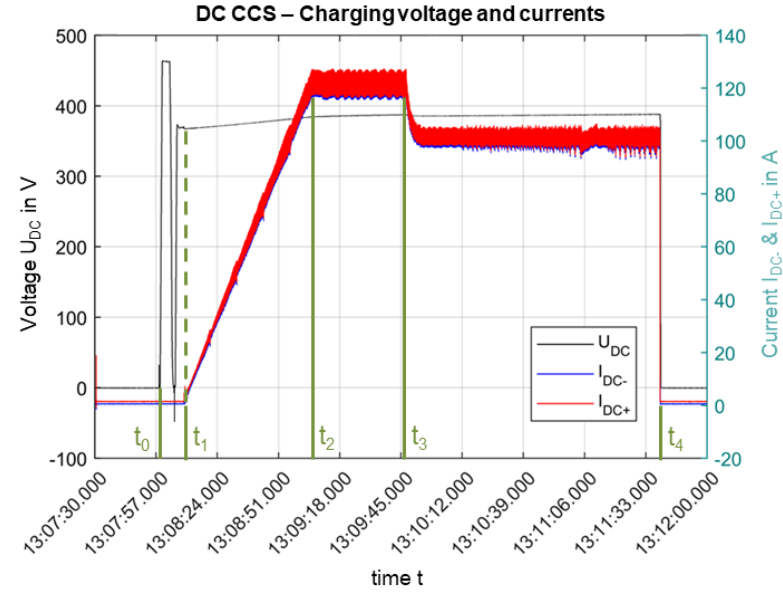

Fig. 7. CCS charging process DC (faultless/normal operation), charging voltage \& charging currents [3]

In the range from $t_{2}$ to $t_{3}=13: 09: 45$ the charging current remains constant at $I_{\mathrm{DC}+1}=120 \mathrm{~A}$. Starting from $t_{3}$ the current is reduced to $I_{\mathrm{DC}+, 2}=100 \mathrm{~A}$. This value remains constant until the end of the charging process at $\left.t_{4}=13: 11: 40\right)$.

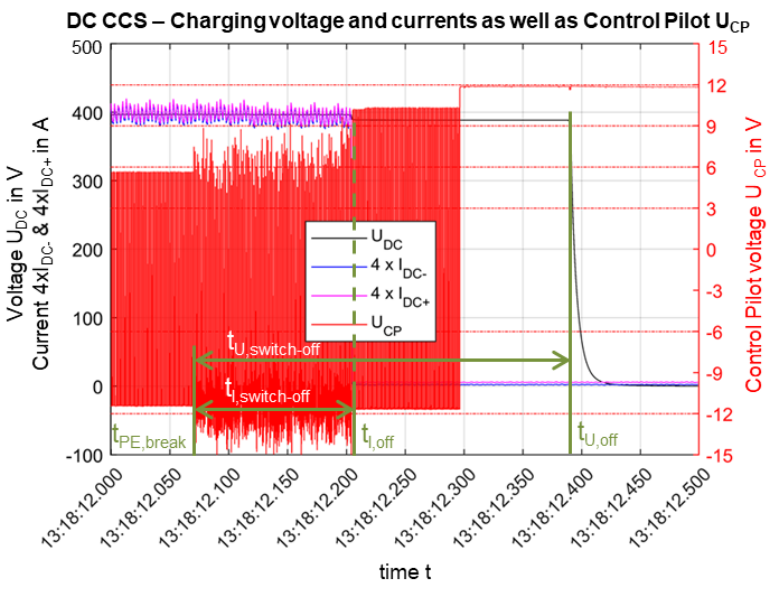

Fig. 8. CCS charging process DC (interruption of PE line), charging voltage, charging currents and Control-Pilot-signal [3]

In Figure 8, an example of a fault occurring during the charging process is shown, in particular, we analyse an interruption of the protective earth conductor PE. In addition to the signals $U_{\mathrm{DC}}, I_{\mathrm{DC}-}$ and $I_{\mathrm{DC}+}$ (each scaled by a factor of 4) the control pilot signal $U_{\mathrm{CP}}$ in the event of interruption of the PE conductor is shown. The interruption was initiated with the distribution cabinet described in the previous section. The potential of the control pilot signal (CP) refers to the protective conductor (PE). Due to this PE reference, the instant of time of the fault initialisation can immediately be identified as $t_{\mathrm{PE}, \text { break }}=13: 18: 12,070$, matching the fault occurrence time $t_{\mathrm{PE}, \text { off. }}$ After this event, the charging current is reduced from $t_{\mathrm{I}, \text { off }}=13: 18: 12,204$ and also the voltage is switched off a little later at $t_{\mathrm{U}, \text { off }}=13: 18: 12,390$. The switch-off time for the current can be identified as $t_{\mathrm{I}, \text { switch-off }}=134 \mathrm{~ms}$, for the voltage as $t_{\mathrm{U} \text {,switch-off }}=320 \mathrm{~ms}$. 


\section{Conclusions and future work}

A survey on appropriate technical standards and in addition, measurements of charging processes as well as fault simulations were carried out in practise and hereinafter the results were analysed and interpreted.

The evaluations of the field tests showed

- that the investigated DC EVCS comply with the production and safety standards in almost all situations;

- that the interruption of the PE conductor during a CHAdeMO (Asian standard) charging process will not be interrupted by the EVCS;

- that in some situations.in case of an insulation fault the insulation monitoring device needs a long time to switch off the charging station.

As a next step a cooperation with a regional and internationally established manufacturer of test equipment was entered in order to develop and produce a mobile testing device for the periodic verification of DC-EVCS regarding the protection against electric shock.

\section{Acknowledgement}

This cooperation project, based on the already achieved knowledge out of [3], is supported by the Austrian Research Promotion Agency (FFG).

\section{References}

[1] European Alternative Fuels Observatory, "Infrastructure stats / Electric vehicle charging infrastructure", http://www.eafo.eu/electric-vehicle-charging-infrastructure (accessed 2018-10-31).

[2] Bloomberg New Energy Finance, "Sustainable Energy in America - $\quad$ Factbook 2018", https://data.bloomberglp.com/bnef/sites/14/2018/02/Sustain able-Energy-in-America-2018-Factbook.pdf (last downloaded 20181031 ).

[3] D. Herbst, Master Thesis: „DC-Ladestationen für Elektrofahrzeuge - Ein Beitrag zur Entwicklung einer Prüfmethode und Prüfeinrichtung zur Erst- und wiederkehrenden Prüfung von DC-Ladestationen für Elektrofahrzeuge“,

Graz University of Technology - Institute of Electrical Power Systems, Graz/Austria, Sep. 2018.

[4] IEC 61851-1:2017-02 "Electric vehicle conductive charging system - Part 1: General requirements", IEC - International Electrotechnical Commission, Geneva/Switzerland, Feb. 2017.

[5] IEC/EN 61851 23:2014 "Electric vehicle conductive charging system - Part 23: DC electric vehicle charging station", IEC - International Electrotechnical Commission, Geneva/Switzerland, Mar. 2014.

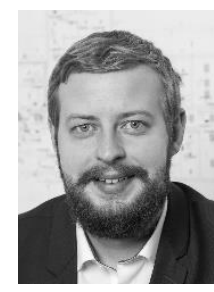

Daniel Herbst, born 1988 in Vienna/AUT studied electrical engineering, specialisation in power engineering at Graz University of Technology. He worked for 5 years in the team of an electrical consulter in Styria in the areas of planning, tendering and construction supervision. In the course of his current work at the Institute of Electrical Power Systems, he deals with the topics of electrical safety and grounding systems of DC charging stations for electric vehicles, measurement technology in electrical power systems and protection concepts at low voltage level.

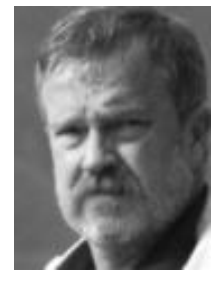

Ernst Schmautzer, Senior scientist at the Institute of Electrical Power Systems, Graz University of Technology, Austria. Professional activities: Inductive, ohmic and capacitive interference, accorrosion, grounding and equipotential bonding systems, protection measures, low-frequency electromagnetic fields, efficient use of electrical energy, load management, smart buildings, smart grids.

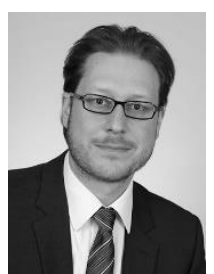

Prof. Schürhuber received his Ph.D. in electrical engineering from Vienna University of Technology in 2003 . From 2003 to 2009 he worked in various fields of electrical power engineering for Siemens Energy, with focus on instrumentation and control. In 2010 he joined Andritz Hydro, where he worked as a senior expert in the Electrical Power

Engineering department, with focus on the electrical behaviour of large hydro installations. Since October 2017 he is head of the Institute of Electrical Power Systems at Graz University of Technology. 